\title{
Mine design impact on operating and capital costs
}

\author{
D Morrison Centre for Excellence in Mining Innovation, Canada
}

R Webb Centre for Excellence in Mining Innovation, Canada

A Akerman Centre for Excellence in Mining Innovation, Canada

H Parsons Centre for Excellence in Mining Innovation, Canada

\begin{abstract}
As new orebodies adjacent to existing operations become deeper and more technically challenging, there is a need to reduce capital demand and operating cost. Implementing conventional designs in deeper deposits can only expect approval if there is a significant increase in ore value, e.g. increased precious-metal values. The effect of increasing depth and technical difficulty is like inflation: continuous improvements may be sufficient to maintain an acceptable return on investment (ROI), but only a step-change in mining practice can offer a significant increase in ROI. The Centre for Excellence in Mining Innovation's (CEMI) objective is to bring innovation to the mining business by helping supply companies take developments with a high technical readiness level (TRL) through to a commercial product and by conducting operational simulations to demonstrate the impact on mining costs. We present several technical innovations focused on economic impact, including increasing advance rates to accelerate access, eliminating operational delays to increase production rate, a new approach to ventilation, and a novel extraction sequence to reduce capital demand and reduce the time to first production. The results of the simulations are presented in terms of improved ROI and net present value (NPV).
\end{abstract}

\section{Introduction}

As the middle-class lifestyle in developed countries becomes a growing aspiration for hundreds of millions of people in developing countries, the long-term demand for metals will increase. This lifestyle has a specific resource demand, for energy, oil, steel, copper and the competition for these resources will intensify. There are only two sources of metal resources: resource extraction from increasingly remote locations burdened by the need to implement infrastructure to bring the resources to market; and extraction from much deeper levels in existing mines that already have transportation infrastructure in place. Given the challenges presented by the physical conditions below $2.5 \mathrm{~km}$ in the mines of the Sudbury Basin, simply continuing with conventional approaches to underground metal mine production or focusing on the automaton of existing production equipment will not likely be sufficient to allow these mines to continue to operate and help meet the long-term growth in demand for metals.

The last major innovation in underground metal mining - the introduction of the bulk stoping mining method and the equipment that made this possible - was introduced and became commonplace over 30 years ago (Bawden 1993). Since then, there has been very little change in technology or approach - the most significant technical advance was the development cemented tailings paste fill as an option (Landriault 1993). From about 1995, many new mines around the world began to adopt paste fill, but mines with existing hydraulic backfill systems were reluctant to convert because they considered only the direct cost of the change, not the potential increase in production that the use of paste fill made possible. Over roughly the same period, the industry has seen an increase in the number of block cave mines around the world as the lowest direct-cost, no-backfill mining method.

Over the last 25 years or so, major mining companies in Canada have funded mining research with many millions of dollars - mostly on rock mechanics to understand the causes and remedies for stress-induced rock failure - a condition that impacts backfilling and non-backfilling mine operations alike. Until the early 
1980s, mining-induced seismicity had been common only in deep reef gold mines in South Africa, a few gold mines in Canada and silver mines in the US (Blake \& Hedley 2003). With the advent of higher-productivity mining methods, the problem of mining-induced seismicity became common in many of the base-metal mines in North and South America, as well as Australia. The research funding saw a dramatic increase in the performance and reliability of microseismic monitoring systems, the quality and effectiveness of ground control systems and the quality of numerical modelling techniques. In Canada, mining companies have collaborated very effectively to develop the kind of tactical and strategic solutions they needed to mitigate the risks created by mining-induced seismicity, other health and safety issues or environmental issues. On operational issues, the Ontario Mining Association often coordinates these efforts; on research issues, other consortia are created to coordinate them, e.g. the Canadian Rockburst Research Program. However, although collaboration was effective for liability issues, this was much less true for productivity-related issues that might provide mines with a competitive advantage (Morrison 2008).

Today, however, the pressures on deep underground mines are increasingly productivity-related more than health and safety related. Health and safety issues will remain an important factor in everything that mine operations do, but the modern era mines typically do not close because of safety reasons; they close because the mineable ore has been exhausted - either mineral resources are too low-value or operating costs are too high. For many mines in Canada at or below $2.5 \mathrm{~km}$ depth, the single most critical cost factor is the power cost to operate the ventilation systems needed to maintain working conditions within regulated conditions (Mining Association of Canada 2005). Many jurisdictions impose work-rest regimens for employees working in very hot and humid environments, and this further reduces human effectiveness - an issue that often triggers an effort to further automate production activities. It may well be that the gains that have long been promised by automation are becoming more achievable as underground communications systems are dramatically improved.

\section{CEMI's recent evolution}

The Centre for Excellence in Mining Innovation (CEMI) was established in 2007 by the Ontario Government and two major mining companies (Vale and Xstrata); for its first five years, it followed the trajectory common to many mining research organisations; delivering mostly rock mechanics studies with some ventilation studies and projects to reduce environmental impact. Collaborative research consortia have been much more effective when trying to address liability issues than in trying to address competitive or pre-competitive research.

In 2012, CEMI began to focus on its core mandate: innovation. There is often no distinction made between innovation and research, and the words are used interchangeably. Our distinction is that successful research has a technical outcome and successful innovation has a commercial outcome; if a new technique or technology is not adopted into common practice - routine operations - then no innovation has taken place. Research can never really fail; it always provides a technical answer, even if it is not the desired answer, while innovation can be, and often is, unsuccessful. Innovation also draws upon more than the new knowledge of a successful research project. It needs operational experience and practical ingenuity to make it successful, overcoming the barriers to operational integration.

\section{Energy consumption}

For more than ten years, the largest single energy cost centre (electricity) in deep underground mines in Canada has been for ventilation (Mining Association of Canada 2005). In northern Ontario, mines have had the opportunity to use natural heat exchanges to cool air during the summer, creating a heat sink in a rock pile in the cold winter to then cool the ventilation air during the summer months. Some mines have the opportunity to cool the air using the volume of very cold water in the bottom of a deep, local lake. At depths below $2.5 \mathrm{~km}$ in the Canadian Shield, the geothermal gradient makes it impossible to deliver cool air from surface without introducing some means of actively cooling the air underground. There are local 
variations in the thermal gradient. It is lower in Timmins, so mines at $2.5 \mathrm{~km}$ are slightly cooler; in Val d'Or, it is slightly higher than in Sudbury, and the mines are hotter. But, for simplicity, we have defined the kinds of conditions experienced in Sudbury at $2.5 \mathrm{~km}$ - both heat and rock stress - as 'ultra-deep' conditions. The very deep, precious-metal mines in South Africa have been in the forefront of delivering cool air to underground mines, but the cost of these methods for bulk, base-metal mines is significantly higher than for narrow reef mines; thus, the technology may not be economically feasible.

One option is the re-introduction of a hydraulic air compressor. Dr D Millar at MIRARCO has redesigned a system built in Cobalt Ontario in 1910. As an example, Figure 1 shows the schematic taken from a US Bureau of Mines Circular (Schultze 1954). In the original facility at Cobalt, river water was diverted upstream of a small waterfall, air is drawn into the water column in the shaft and compressed on its way down to the horizontal drift. In the drift, the compressed air rises to the roof where it is drawn off for future use, and the water pressure is sufficient to return the water to surface up a shorter shaft into the river below the waterfall. This system created fresh compressed air at very low cost with no moving parts. The height of the shaft determines the degree of compression. The original installation was $305 \mathrm{~m}$ high and produced compressed air at $9.142 \mathrm{~kg} / \mathrm{cm}(1,000 \mathrm{ft}$ high and $130 \mathrm{psi}$ pressure or $9 \mathrm{bar})$.

Dr Millar's re-design involves a small amount of re-pumping so it is not reliant on natural waterfall diversion. The compressed air can be delivered by pipeline to the hottest areas of the mine, typically dead-end drift development headings and other areas with no flow-through ventilation, where the adiabatic expansion of the compressed air cools the heading and reduces the humidity, creating a more comfortable work environment. The nine-fold expansion of the compressed air also pushes air out of the heading without operating fans to push or pull air in and out of the heading, further reducing energy costs.

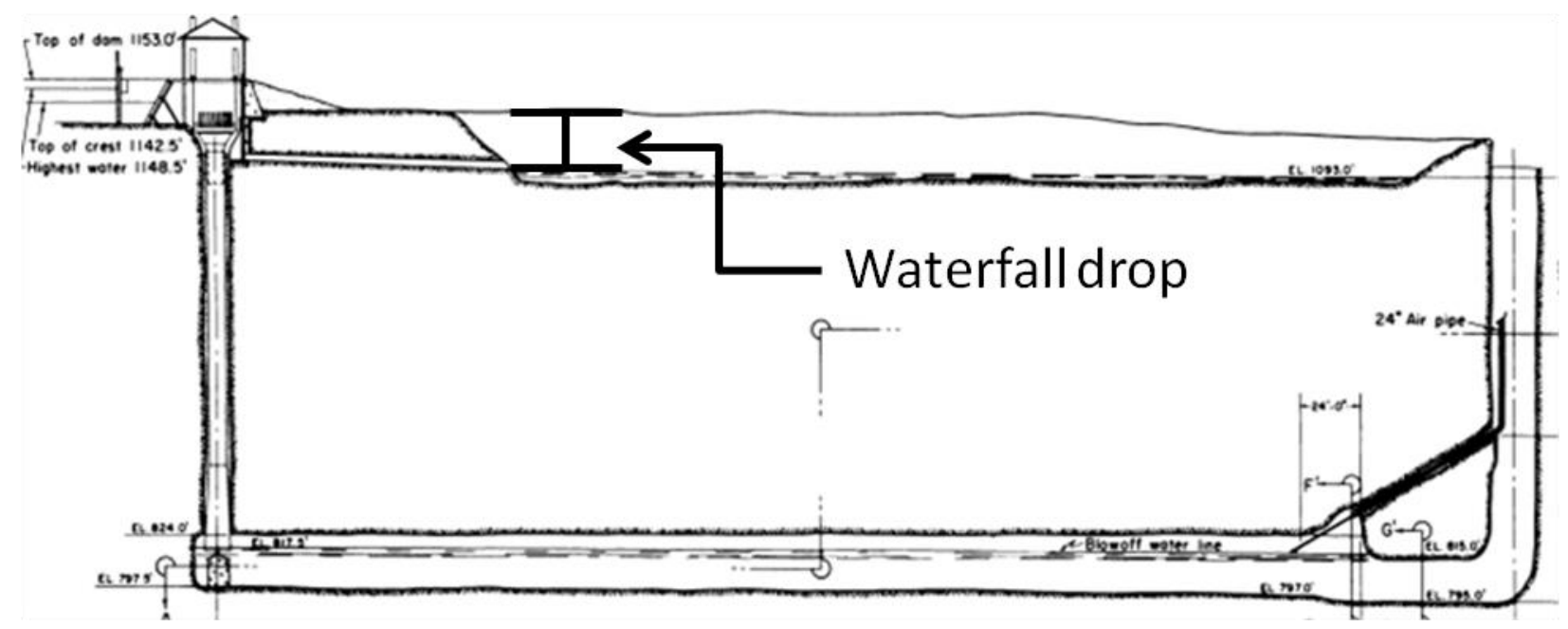

Figure 1 A hydraulic air compressor schematic similar to the 1910 installation in Cobalt, Ontario

\section{$4 \quad$ Improving mine production}

Many of the deep underground mines in Canada are challenged by the geotechnical and temperature conditions and the logistics of long supply lines - all of which make it more difficult to show a return on capital for new deep orebodies, especially base-metal deposits. Simply continuing with the conventional production systems makes the development of new deposits dependent on the grade of the material.

The first issue is the rate of advance for long, single-heading development. Canadian mines often develop inclined drives from the bottom of a hoisting shaft, usually 5 to $5.5 \mathrm{~m}$ wide and high $\left(25-30 \mathrm{~m}^{2}\right)$, and this affects the NPV and the time to first production. In Ontario, because of the potential for rockbursting from the roof, walls and face of drifts below $2.4 \mathrm{~km}$, the time taken for ground support installation increases the cycle time and reduces the single-heading advance rate to around $3.5 \mathrm{~m} /$ day. 
CEMI has developed a canopy system (Figure 2) that will help accelerate drift development rates by allowing concurrent activities to occur in the heading after broken rock has been removed. The canopies are moved into position by the loader (load-haul dump unit (LHD)) at the end of the face clearing activity and are designed to expand laterally and vertically from the compact format. The frame is pushed up against the roof and walls of the drift, assuming no overbreak, to reduce dynamic impact of rock on the frame. The expanded format allows every type of production equipment to pass through the expanded frame, including a second canopy in its compact format. For bursting conditions, the frame has the ability to absorb a dynamic load of $12.5 \mathrm{kj}$ per square metre (equivalent to a $1 \mathrm{~m}$ thick slab accelerated at $3 \mathrm{~m} / \mathrm{s}$ ). The face shield is another option that mitigates the risk of injury from loose or from strain-energy rockbursts at the face.

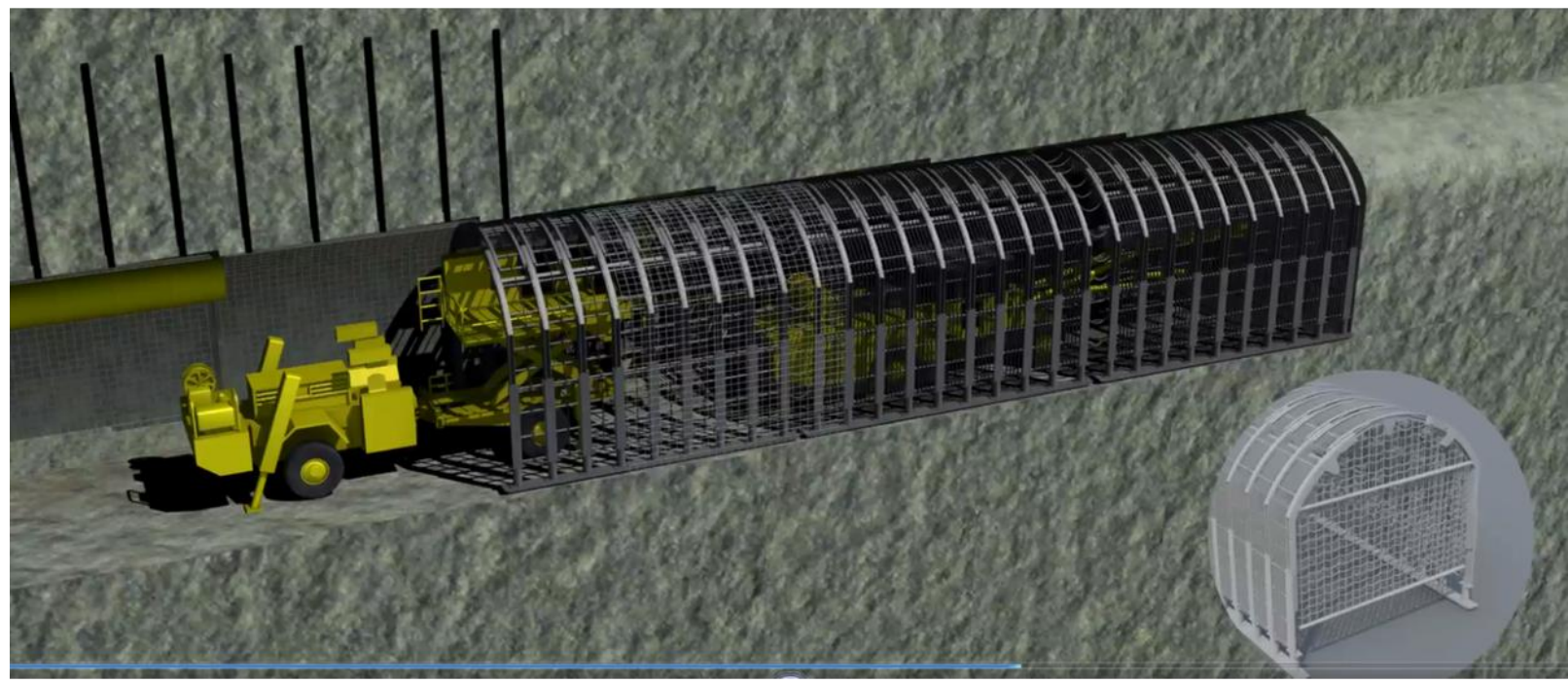

Figure 2 Schematic of three canopies protecting equipment for simultaneous face activities

Under the protection of the canopy, crews can complete face drilling and charging while ground support is installed behind them, and the face shield (inset in Figure 2) offers additional protection against loose from the face. Ground reinforcement is installed from inside the canopy with the equipment that is standard for a given mine and through the mesh that is temporarily attached to the outside of the canopy frame. The advantage to the operation will depend on the operating protocols in any given mine, such as blast-at-will or centralised blasting. Concurrent activities in the heading always reduce the development cycle time, in this case by the time taken for the ground support cycle. The issue is the ability of the mining operation to use the time offered by the canopy system. If the operation is constrained by end-of-shift blasting, it can be difficult to make productive use of this time and so increase the daily $\mathrm{m} /$ day advance rate. In the case of a dedicated long-length drift development, a blast-at-will protocol is common, and making use of the reduced cycle time created by the use of the canopy can make a significant difference to the daily advance rate. Of course, a single canopy can be used in locally difficult situations where additional protection for work crews is considered appropriate.

Simulations show that the application of the three-canopy system cannot make two rounds per day possible in a 5 by $5 \mathrm{~m}$ heading (or greater). The second phase of the Rapid Development Project is to focus on reducing the time taken to remove broken rock from the face and accelerate the re-entry of the face equipment. The success of this phase will allow for one standard advance every shift even in an end-of-shift blasting protocol, and, for blast-at-will protocols, even greater advance rates will be possible. Increased daily advance rates will substantially reduce development cost, while more rapid access to the orebody reduces time to first production and improves the net present value (NPV). 


\section{$5 \quad$ Improving production rate}

For open stoping with backfill, there are many phases to the production cycle, so there are several options to improve the potential for increased production. Improvements in the drilling and blasting processes can prove ineffective unless the operation can improve the rate of backfilling.

Hydraulic cemented tailings fill and cemented rock fill are common in many mines. Generally, for very deep shaft-mines with large-volume stopes, pipeline delivery is considered the most cost-effective option; for shallow mines with relatively small-volume stopes, truck delivery may be more cost-effective.

Hydraulic cemented tailings fill remains very common despite its major disadvantages, e.g. the preparation time for barricades and drainage towers installation, the effective delivery rate (reduced by delays for drainage) and, finally, clean-up costs (re-pumping drainage water and managing fines).

Cemented tailings paste fill combines the advantages of pipeline delivery without the disadvantages of costly preparation and clean-up associated with hydraulic fill. There is sufficient water in the paste only to ensure delivery to the stope and to hydrate the cement; there is no excess water and therefore no need for water-retaining barricades or for drainage systems and protocols. Once a waste pile (or berm) is placed in the drawpoint, tailings paste fill can be poured 24 hours per day until the stope is filled. The speed and simplicity of paste backfill delivery makes it possible to reduce stope cycle times and increase mine production rates. Figure 3 shows the effect on stope cycle time using cemented hydraulic fill versus tailings paste (Morrison et al. 2014). In this case, there is a minor reduction in cycle time, but this is not sufficient to justify replacing an existing hydraulic fill system with a new paste fill system.

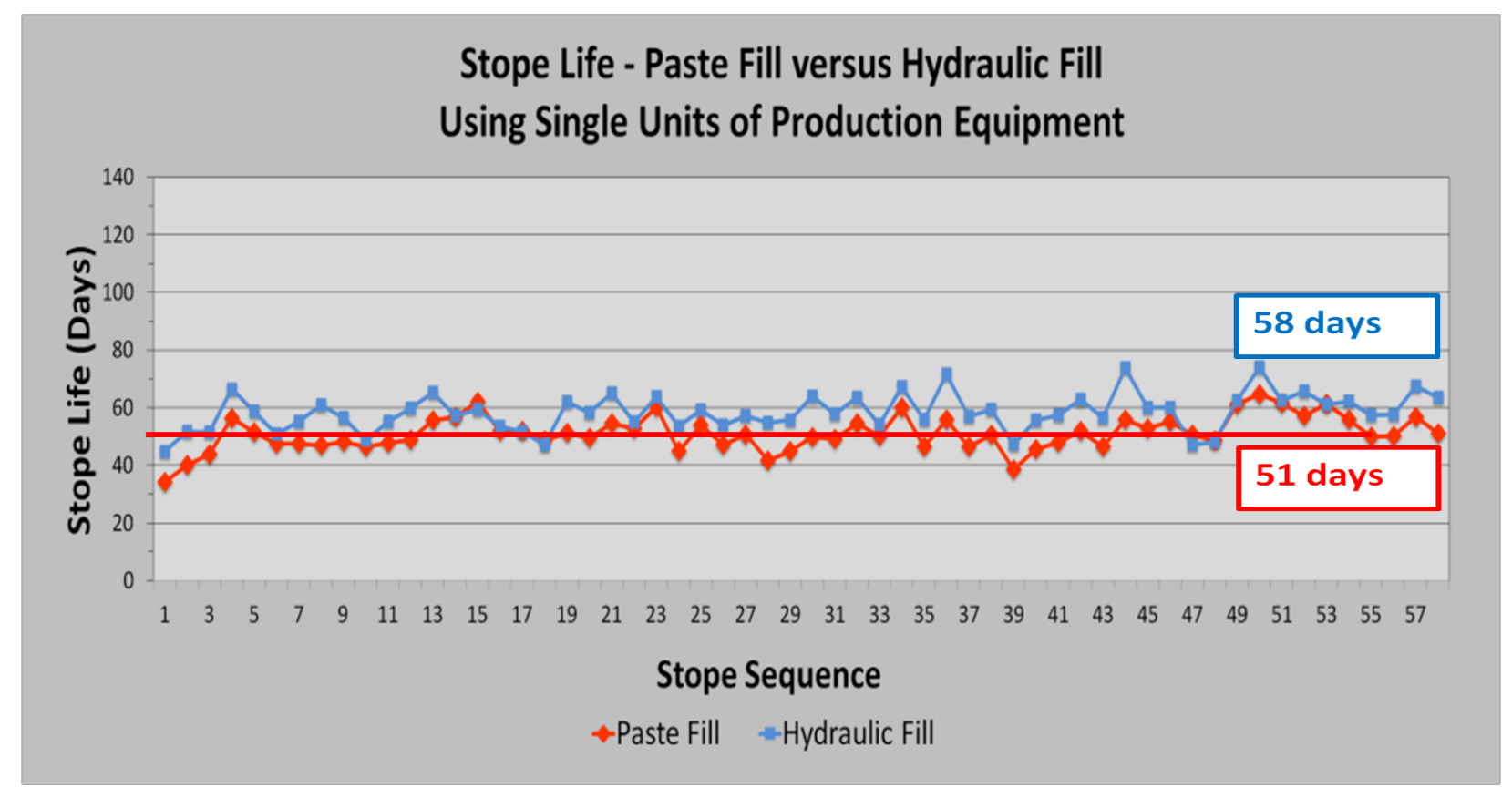

Figure 3 Base case simulations of stope cycle time using hydraulic backfill and paste fill

Figure 4 shows the results of additional simulations to examine the potential to increase production by replacing cemented hydraulic tailings with cemented tailings paste. The top-left graph (Figure 4(a)) is the base case shown in Figure 3, and the top-right graph (Figure 4(b)) shows the effect of doubling the number of loaders (LHDs) - increasing the mucking or bogging rate. The bottom-left graph (Figure 4(c)) shows the effect of doubling the amount of production drilling, but leaving the number of loaders (LHDs) the same as the base case; bringing more stopes into production. In this case the cycle time for hydraulic fill begins to increase because, with a fixed work-force, there is not enough time to prepare stopes for fill and the cycle time actually increases. The bottom right graph (Figure 4(d)) shows the effect of doubling both the number of loaders and the amount of stope drilling, with the effect of reducing the paste fill cycle time and further increasing the hydraulic fill cycle time. 
Tailings Paste-fill

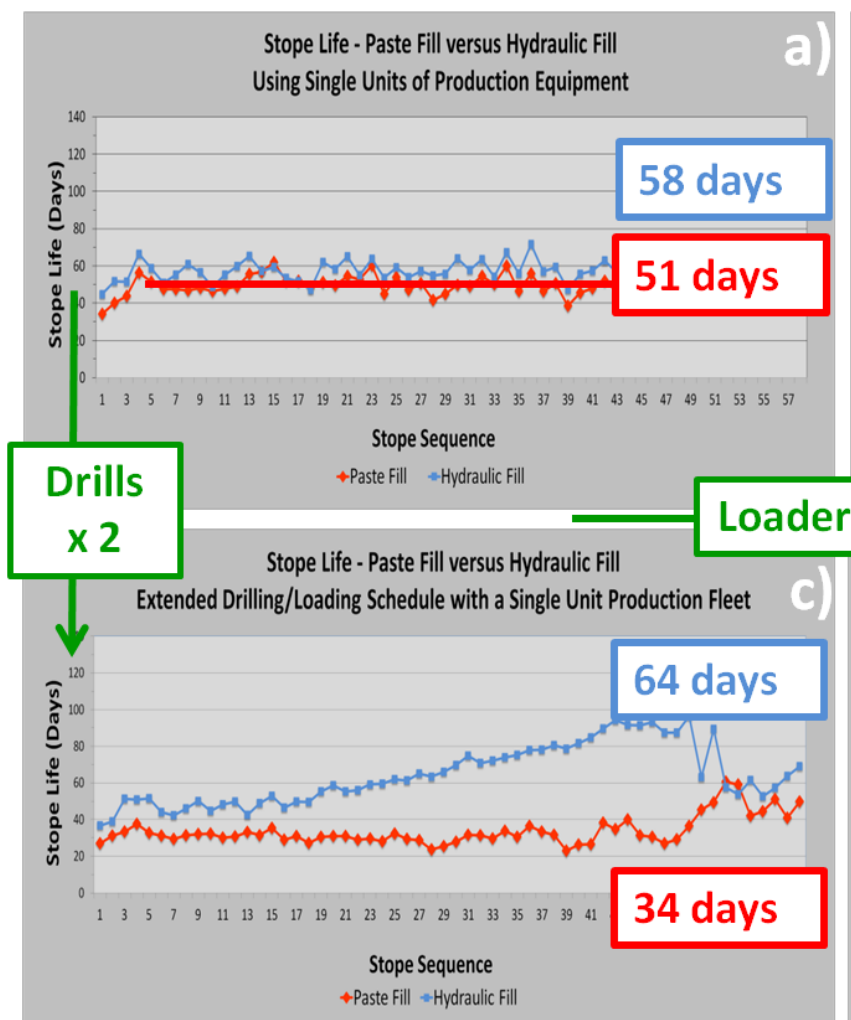

Hydraulic fill

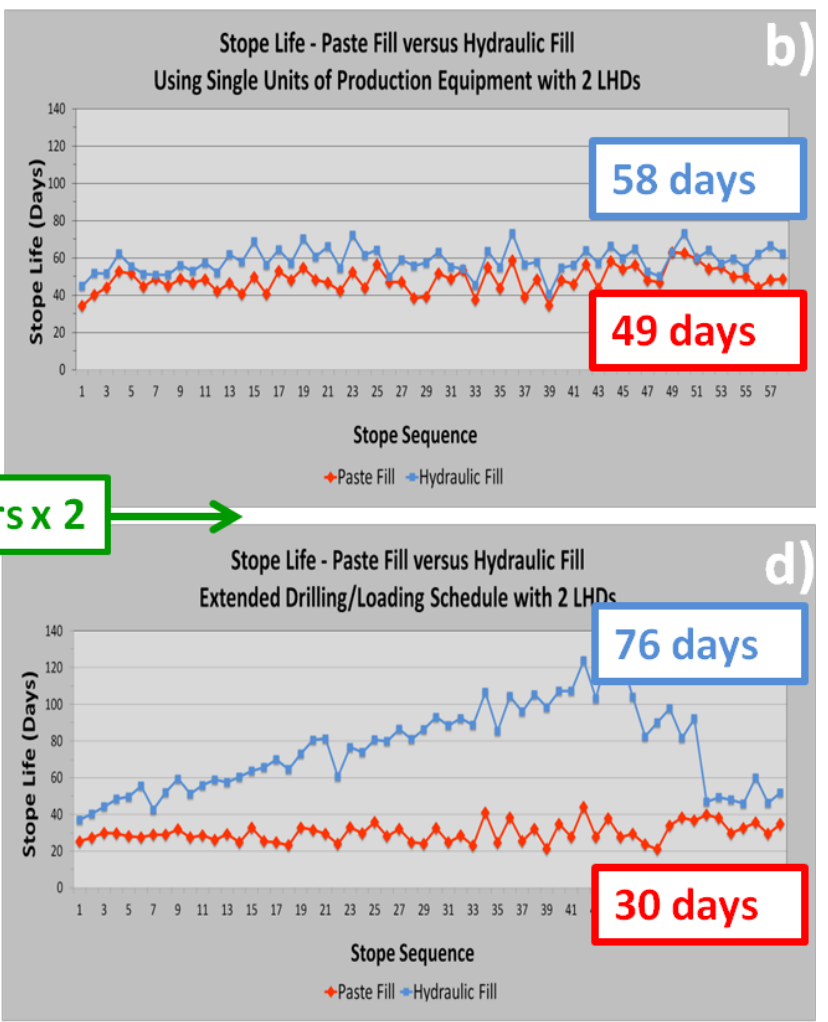

Figure 4 Comparison of four simulations; stope cycle times for hydraulic and paste backfill

These comparisons show that using paste fill creates a significant reduction in stope cycle time. Essentially, it is the hydraulic backfill rate that limits the rate of production; mines using conventional hydraulic tailings are effectively limiting the amount of production drilling to match the backfill rate and so keep whole production system in balance. Introducing tailings paste fill can offer mines the opportunity to dramatically reduce stope cycle time from 58 to 30 days and, therefore, offer a significant increase in production.

This does not mean that a mine can necessarily take advantage of the increase that tailings paste offers. The hoisting system of a shaft-mine or the haulage ramp is usually at, or close to, capacity, and increasing the transportation of ore to surface system cannot be achieved unless other changes are made. Most mines bring all development waste to surface, expending energy to bring value-less material to surface. For shallow mines, this is a convenience; however, as mines get deeper, the cost to hoist value-less material becomes expensive, especially if it prevents hoisting valuable material. Setting up a logistical loop to store and manage waste-rock for consumption in the backfill system could free up hoisting capacity for more ore production if it were available. Operating at depths greater than $2.5 \mathrm{~km}$ below surface, all mines will have to significantly improve productivity and make better use of resources if it is to become possible to mine profitably below $2.5 \mathrm{~km}$.

\section{$6 \quad$ Reducing up-front capital cost}

The conventional approach to open stoping an orebody below the existing crusher and hoisting shaft is to identify the lowest production level, drive a ramp or decline to this level and establish a stope extraction sequence working laterally and upwards, level by level, towards the top of the deposit. As mines have become deeper, the effect of increased ambient stress levels forces the reduction in stope height to reduce dilution and stope collapse, and so decreasing the level interval. As an example, while mining above $2 \mathrm{~km}$ deep in the Sudbury Basin, stopes were typically 50-60 m high; but at depths close to $2.5 \mathrm{~km}$, the stable stope height is approximately $35 \mathrm{~m}$ high. This has two important effects: it increases the amount of 
development required for each tonne of deeper ore mined, and the smaller stopes increase the need for a faster cycle time.

The bottom-up approach was adopted many years before tailings paste fill was developed; it was relatively low-quality hydraulic backfill and used only the amount of cement necessary to ensure stable fill walls during the extraction of secondary stopes. However, the possibility of using an engineered, high-strength cemented tailings paste - perhaps augmented by crushed waste-rock - makes it possible to make a higher quality backfill and to design it to be suitable as overhead fill.

Figure 5 shows a schematic of the two approaches: the bottom-up sequence and the top-down sequence. In the top-down simulation an uphole blasting method under backfill was used, but future work will include a downhole drilling alternative, under backfill, perhaps using a canopy for additional protection. The top-down approach makes it possible to use the efficiencies of the open stoping method but drastically reduce the upfront capital development needed to go to the bottom of the deposit before achieving first production.
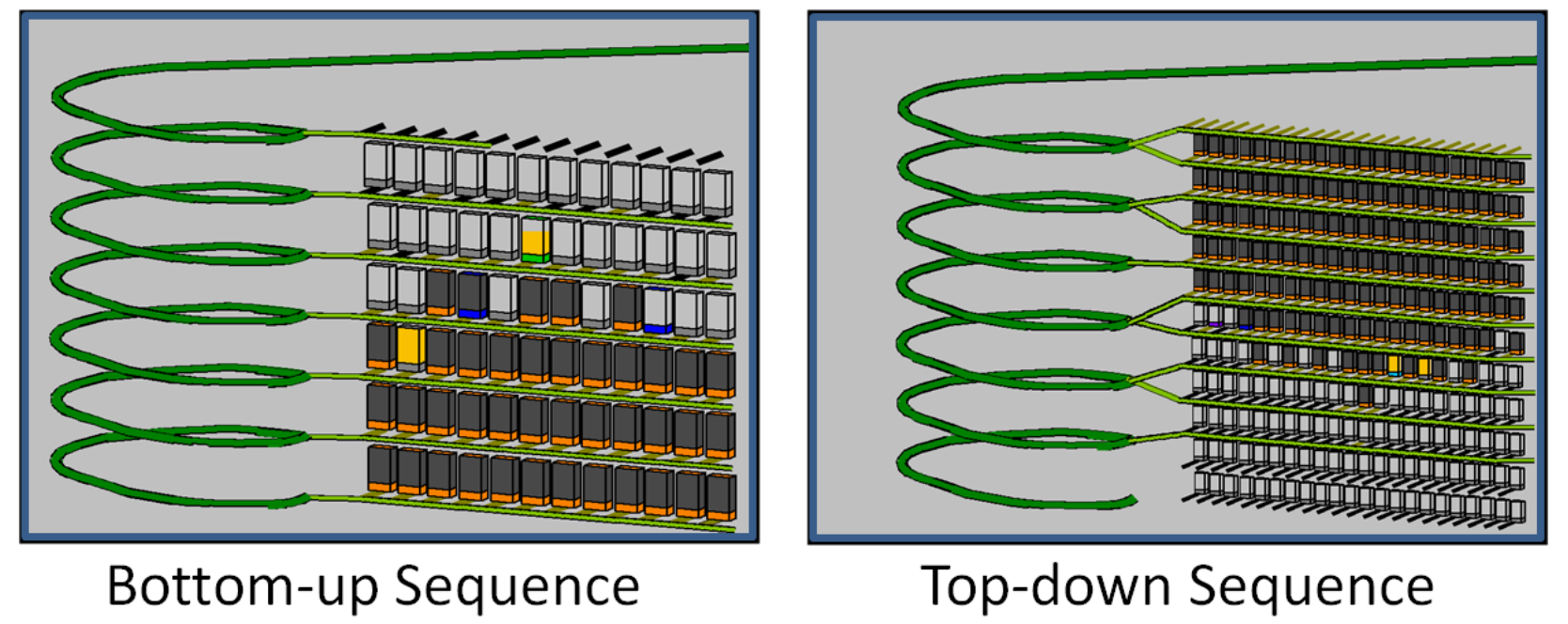

Figure 5 Schematic of two approaches to mining a generic orebody: bottom-up and top-down

A simulation of both extraction sequences of the same generic deposit were used to show the effect on the NPV, presented in Canadian dollars in Figure 6. Although several ore transportation alternatives were also simulated, they were relatively ineffectual and truck hauling ore up the decline is the base case for both sequences, overlain by the red and green lines. The effect the top-down method is to reduce the amount of upfront capital expenditure necessary before first production is achieved. The financial implications of these two approaches are highlighted with the red (bottom-up) a green (top-down) dashed lines. Clearly, the top-down approach results in a higher NPV following lower upfront capital and a faster return on the capital investment. This is despite the higher cost per tonne for the small-height stopes; however, at depths greater than $2.5 \mathrm{~km}$, the higher stresses will likely make the cost of small-height stopes unavoidable.

The top-down mining approach is only one alternative - one made possible by a focus on the delivery of consistently high-quality past backfill. But regardless of the techniques or approaches used, if mining future 'ultra-deep' orebodies are to be economically viable, some means of moving the NPV graph upwards and to the left must be achieved. This is the only way that we ensure that the project is approved and that shareholders achieve the best possible return. 


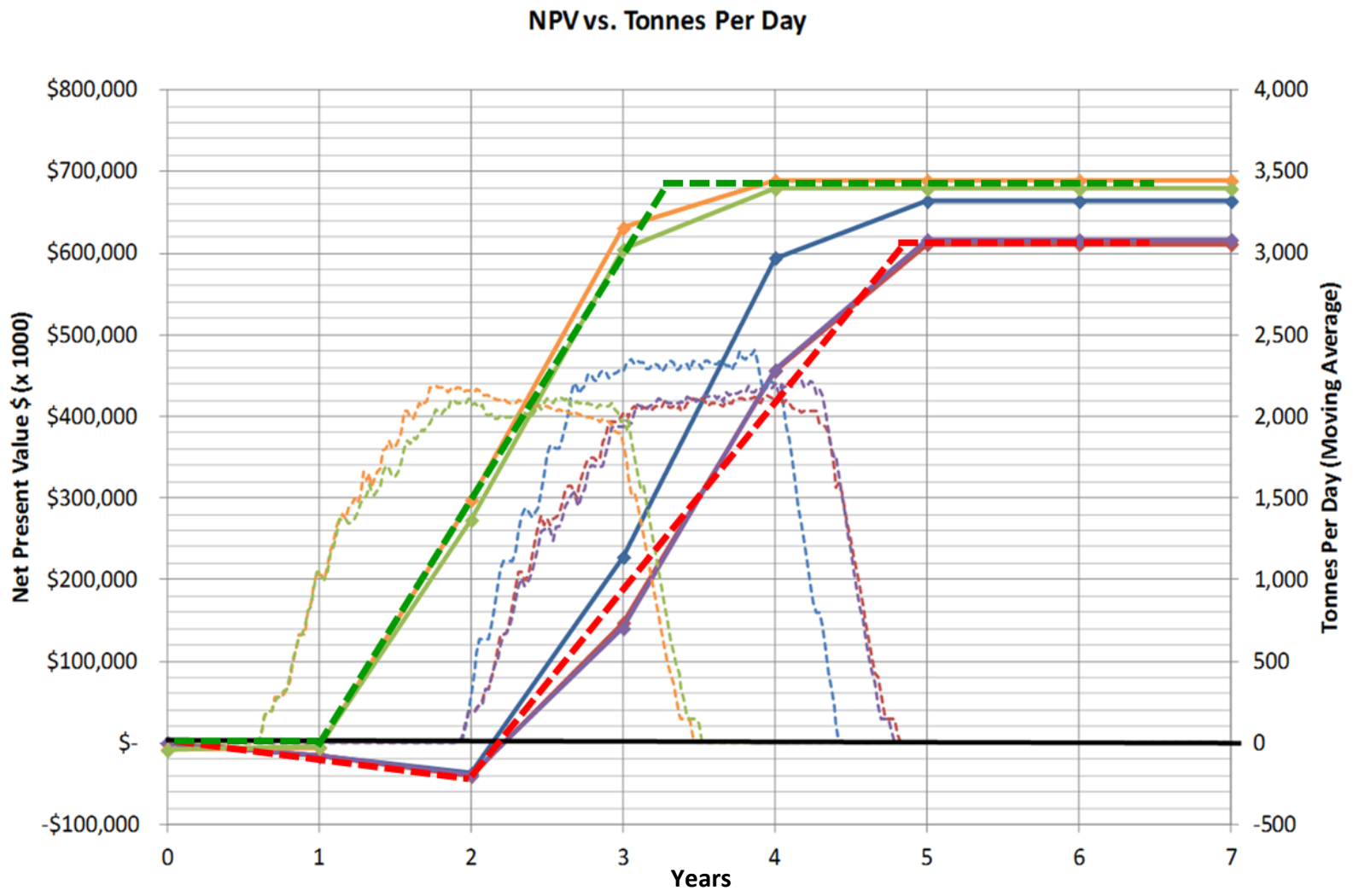

Figure 6 Comparison of the NPV (in Canadian dollars) for two approaches to a generic orebody

\section{Automation}

We have not addressed the issue of automation; there are many organisations spending time and money on this, and the underground metal mines are only now getting the kind of communications systems in place to make achieving significant gains from automation possible. The larger question is what production process should be automated? For over 30 years, there have been attempts to automate exploration and production drills as well as loaders and trucks, with varying degrees of success. However, the issues of heat management and the cost of large-face drift developments at depths greater than $2.5 \mathrm{~km}$ mean that continuing to rely on loaders and trucks for ore transportation is unlikely to be successful, except for the very highest grades of material.

The current equipment fleet in most underground mines requires maintenance manpower that is roughly equal to the production manpower. In terms of labour cost, maintenance is the large overhead component in the system, and increasing automation of this type of equipment fleet will increase this cost. Continuing to automate existing technologies in order to eliminate manpower is a distraction from the main task at hand. At CEMI, we believe that the right approach is first to lean the entire production process, changing technology as necessary to achieve a smooth, intervention-free process. This will not be easy to achieve, but we believe it to be essential, while subsequently automating this kind of production system is the only approach that can assure the future of the underground mining industry.

\section{Conclusion}

There are only two sources of metal resources: extraction from increasingly remote locations burdened by the need to implement transportation infrastructure to bring the resource to market, and extraction from much deeper levels in existing mines that already have transportation infrastructure in place.

To meet this demand, it is clear that the productivity of most base-metal mines $2.5 \mathrm{~km}$ below surface will have to improve their performance significantly. Given the cost of managing the physical conditions below $2.5 \mathrm{~km}$, simply continuing with conventional approaches and focusing on automating existing production 
equipment is unlikely to make the necessary difference to capital and operating costs. The technological developments the industry adopts must also enable significant changes in mine design. A major change in the production systems used by mines operating at more than $2.5 \mathrm{~km}$ below surface is essential - and urgent. The issue for the mining industry is whether there is sufficient leadership to fund the changes that will deliver results in the time available.

\section{References}

Bawden, WF 1993, 'The use of rock mechanics principles in Canadian underground hard rock mine design', in JA Hudson (ed.), Comprehensive rock engineering, Pergamon Press, vol. 5, pp. 247-290.

Blake, W \& Hedley, DGF 2003, Rockbursts: case studies from North American hard-rock mines, Society for Mining, Metallurgy, and Exploration, Inc., Littleton, CO.

Landriault, DA \& Lidkea, W 1993, 'Paste fill and high density slurry fill', in WF Bawden \& JF Archibald (eds), Proceedings of the International Congress on Mine Design, A.A. Balkema, Rotterdam, pp. 229-238.

Mining Association of Canada \& Natural Resources Canada 2005, Benchmarking the energy consumption of Canadian underground bulk mines, Mining Association of Canada \& Natural Resources Canada, Ottawa, ON.

Morrison, DM 2008, 'Canadian mining - changing to meet the future?', in J Hadjigeorgiou (ed.), Proceedings of the Third International Symposium on Strategic versus Tactical Approaches in Mining, Université Laval, Quebec.

Morrison, DM, Parsons H \& Akerman, A 2014, 'Towards continuous bulk production from below $2.5 \mathrm{~km}$ ', in M Hudyma \& Y Potvin (eds), Proceedings of the Seventh International Conference on Deep and High Stress Mining, Australian Centre for Geomechanics, Perth, pp. 57-63.

Schulze, LE 1954, Hydraulic air compressors, Bureau of Mines Information Circular 7683, United States Department of Interior, Washington DC. 
